\title{
Aceite de la palma de seje Oenocarpus bataua Mart. por su calidad nutricional puede contribuir a la conservación y uso sostenible de los bosques de galería en la Orinoquia Colombiana
}

\author{
Oil from seje palm Oenocarpus bataua Mart. due to its nutritional \\ quality may generates conservation and sustainable use of riparian \\ forest in the Colombian Orinoquia
}

\author{
Óleo de palma seje Oenocarpus bataua Mart. pela sua qualidade \\ nutricional pode contribuir para a conservação e uso sustentável das \\ florestas gerado galeria no Orinoquia colombiana
}

Álvaro Ocampo-Duran ${ }^{1 *}$, Andrea P. Fernández-Lavado ${ }^{2 *}$, Francisco Castro-Lima ${ }^{3 *}$

\begin{abstract}
Zootecnista, MSc, PhD, DIC, Universidad de los Llanos.
MVZ, Especialista, Universidad de los Llanos.

Ingeniero Agrónomo, Fundación Horizonte Verde.

Grupo de Investigación en Sistemas Sostenibles de Producción con énfasis en Palmas Tropicales
\end{abstract}

Email: aocampo@unillanos.edu.co

Recibido: Noviembre 01 de 2011

Aceptado: Octubre 2 de 2013

\section{Resumen}

Los bosques de galería de los Llanos Orientales de Colombia, muchos de ellos ricos en palma de seje (Oenocarpus bataua Mart.), han sido fundamentales como soporte nutricional de comunidades ancestrales de la región. La extracción del aceite de seje se trabajó en la Reserva Natural Las Unamás, ubicada en el municipio de San Martín, a una altitud de 300 m.s.n.m, vereda La Novilla, Departamento del Meta, Colombia, en tres bosques de galería de 900 ha. La presencia de palma de seje y la extracción de su aceite ilustran el potencial de uso sostenible del bosque, con un producto como el aceite de seje similar o superior al aceite de oliva, adecuado para el consumo humano o uso estratégico en alimentación animal. Se determinó el número de palmas por hectárea en el bosque de galería, la calidad del suelo y se evaluaron protocolos para el mejoramiento del proceso de extracción de aceite respecto al método tradicional, con manejo de la temperatura durante el proceso. Para el protocolo 1 tradicional la extracción de aceite máxima fue de $2,5 \%$, siendo mayor la extracción del protocolo 1 (4,26\%), que la incrementó en 70\% respecto al sistema tradicional. El número de palmas promedio fue de $187,7 \mathrm{ha}^{-1}, 67 \%$ productivas $\left(125,7 \mathrm{ha}^{-1}\right)$ y $33 \% \mathrm{im}-$ productivas en desarrollo $\left(62 \mathrm{ha}^{-1}\right)$. Los suelos donde se producen estas palmas tienen alta acidez, bajos contenidos de fósforo y nitrógeno, baja capacidad de intercambio catiónico y altos contenidos de aluminio y hierro, pero su productividad parece estar ligada al proceso orgánico del ciclaje de nutrientes por la hojarasca y la presencia de microorganismos en la capa superficial del suelo. La composición del aceite de seje no fue afectada por la maduración del fruto, pero el fruto maduro produjo más aceite. El aceite de seje es rico en ácido oleico en proporción similar al aceite de oliva, con menor contenido de ácido linoleico que este último, pero mayor contenido de ácido linolénico. La obtención de un producto como el aceite 
de seje, de alto valor nutricional, producto del bosque de galería, podría contribuir a su conservación y al uso sostenible del bosque.

Palabras Claves: Aceite de seje, bosque de galería orinocense, ácido linoléico, ácido linolénico, ácido oleico, Oenocarpus bataua Mart. y palma de seje.

\begin{abstract}
The riparian forest on eastern plains of Colombia, many of them rich on seje palm (Oenocarpus bataua Mart.), have been meaning as nutritional support for ancestral communities of the region. The extraction of seje Oil was done in the Natural Reserve the Unamas, San Martin county, 300 a.s.l., Meta department, Colombia. A three riparian forest of 900 hectares was used for the study. The seje palm and its oil extraction illustrate the potential forest sustainable use, with seje oil, which is similar or superior to olive oil, edible for human consumption and strategic potential use for animal nutrition. A density of palms in the riparian forest was established; soil quality and protocols for the seje oil extraction were evaluated, trying to improve the traditional oil extraction protocol, management the temperature during the process. For the traditional protocol 1 the maximum oil extraction was 2,5\% while with protocol 2 it was of 4,26\% improving the oil extraction on $70 \%$. The average palm density was $187,7 \mathrm{ha}^{-1}$ where $67 \%$ of the palms were on production $\left(125,7\right.$ palms ha $\left.^{-1}\right)$ and $33 \%$ were unproductive on development (62 palms ha $\left.{ }^{-1}\right)$. The soil were the seje palm is produced is acid, low in phosphorus and nitrogen content, and high aluminium and iron concentration, but the forest productivity seems to be linked to nutrient cycling by trash and microorganism on the superficial soil layer. The seje oil composition was not affected by fruit ripeness but the fruit ripe produced more oil. The seje oil is rich on oleic acid similar to olive oil, with lower linoleic acid but higher linolenic acid content. The seje oil product of high nutritional value, a product of riparian forest, should contribute to forest conservation and its sustainable use.
\end{abstract}

Key words: Seje oil, riparian orinoquia forest, oleic acid, linoleic acid, linolenic acid, Oenocarpus bataua Mart., seje palm.

\title{
Resumo
}

As matas de galeria nas planícies orientais da Colômbia, muitos deles ricos em Palma de seje (Oenocarpus bataua Mart.), têm sido fundamentais como apoio nutricional das comunidades tradicionais da região. A extração de óleo está trabalhando seje reserva natural Unama, município de San Martín, Meta departamento, Colômbia, em três matas de galeria de 900 hectares. A presença de Palma de seje e extração do óleo mostram a alta produtividade dessas florestas, com um produto como seje óleo similar ou superior ao azeite de oliva, adequada para o consumo humano ou utilização estratégica de alimentos para animais. Foi determinada a densidade de palmeiras na galeria de qualidade do solo da floresta, e avaliados dois protocolos para melhorar o processo de extração de óleo em comparação com o método tradicional, com controle de temperatura durante o processo. A máxima extração do óleo para o protocolo tradicional foi de $2,5 \%$, a maior sendo a extração de um protocolo de 4,26\%, o aumento da extração em comparação com o sistema tradicional em $70 \%$. A densidade média de 187,7 foi obtido palmas ha ${ }^{-1}, 67 \%$ rendimento $(125,7$ palmas ha-1) e $33 \%$ improdutivo em desenvolvimento (62 palmas ha-1). Os solos ocorrem estas palmeiras têm acidez elevada, baixo teor de fósforo, azoto, a capacidade de troca de catiões baixo e alto teor de ferro e de alumínio, mas a produtividade parecem estar relacionados com o processo de mulch orgânico e na presença de micro-organismos no solo. A composição do óleo não foi afetada pela seje o amadurecimento de frutos, mas o fruto maduro produziu mais óleo. O seje óleo é rico em ácido oleico semelhante ao azeite de oliva, ácido linoleico menos do que o segundo, mas maior o teor de ácido linolénico. Obtenção de um produto como o óleo seje, alto valor nutritivo, mata de galeria do produto, deve contribuir para a conservação e uso sustentável da floresta.

Palavras chave: Óleo Seje, Floresta de galería, linoléico, linolênico, Oenocarpus bataua Mart., oléico e Palma Seje. 


\section{Introducción}

Los bosques ocupan el 31\% de la superficie terrestre, encontrándose en Latinoamérica y el Caribe el 22\% del área total de bosques. El 49\% del área de esas regiones son bosques (FAO, 2011). Estos albergan al menos el $75 \%$ de las especies continentales (Pérez et al., 2007). En Colombia, la región de los Llanos Orientales presenta características edafoclimáticas con una alta complejidad de formaciones vegetales (Sarmiento, 1994). En ellos, los bosques de galería y relictos de bosque primario son ecosistemas estratégicos para el mantenimiento del equilibrio ecológico y la conservación de la biodiversidad, con múltiples servicios ecosistémicos como la regulación climática e hídrica, conservación de suelos y depuración de la atmósfera, corredores biológicos para la fauna y banco genético de flora nativa de la región (WWF, 1998; Lasso C A et al., 2011).

En los bosques de galería las palmas son uno de los elementos más insignes de la biodiversidad del trópico y el subtrópico (Henderson et al., 1995). Además de su importancia ecológica en los ecosistemas de bosques y selvas, su llamativa presencia, alta diversidad y usos, han identificado a las palmas como complejos de vida del hombre y los animales (Paniagua, 2005). La Palma de seje, Unama o Mil Pesos (Oenocarpus bataua Mart.), es una de las especies más comunes en los Ilanos de Colombia (Henderson et al., 1995) y la más notable de todas las palmeras oleaginosas existentes en la cuenca del Orinoco por la calidad insuperable de su aceite (Sellier 1957). Palma de estipe solitario, liso y conspicuamente anillado, alcanza alturas de 4 a 26 metros, monoica con inflorescencias infrafoliares, llegando a tener hasta dos metros de largo, incluyendo pedúnculos florales de hasta $40 \mathrm{~cm}$ (Núñez-Avellaneda \& Rojas-Robles, 2008). Los frutos inmaduros son de color verde y al madurar se tornan mordos o negros (Balick, 1992).

La palma de seje ha sido empleada como alimento básico en los Ilanos, así como en la región Amazónica y el Pacífico colombiano. Es utilizada por la población local, indígenas, campesinos y colonos, como fuente de alimento, (aceite, "chicha", "leche", alimento fresco), medicina, fibras, material de construcción, artesanías y objetos manuales (Jativa \& Alarcón, 1994; Vélez, 1992, Vallejo, 1993; Ocampo, 1998). Tales características hacen que esta palma tenga una alta potencialidad para el aprovechamiento sostenible de poblaciones silvestres, por su amplia distribución y sus densidades relativamente altas (Peters et al. 1989, Miller, 2002). Así mismo, su uso se ha descrito desde el siglo XII en diferentes tribus nómadas de los Llanos
Orientales (Ocampo, 1997, 1998), como los indígenas del Vichada y del Vaupés, que emplean el aceite como manteca para preparar sus comidas (García, 1974). El nombre Oenocarpus se deriva de dos raíces griegas: oinos = vino y karpos = fruto, significa "fruto de vino" (Balick, 1986). Recibió este nombre de los primeros exploradores de América, que observaron la utilización del fruto en refrescos y bebidas altamente nutritivas (Wallace, 1853; Balick \& Gershoff, 1994).

El fruto de la palma de seje es conocido por la calidad nutricional del aceite, similar en composición al aceite de oliva (Balick, 1982). Su jugo es comparado con la calidad de la leche materna humana en su contenido de grasa, proteínas y carbohidratos, y su poder calórico contiene el $55,3 \%$ de las calorías de los aceites, $7,41 \%$ de proteína y $37,3 \%$ de carbohidratos (Collazos y Mejía, 1987).

Aquí se describen los resultados de la composición florística y el número de palmas de seje por hectárea en los bosques de galería de una reserva natural privada; dos protocolos para la extracción del aceite de seje y la cantidad extraída; la composición nutricional del aceite $y$ el contenido de macro y micro minerales del suelo donde habita esta palma. Así se demuestra el alto valor de producción de la especie, que es un componente importante de estos bosques que demandan su conservación y el uso sostenible de sus productos.

\section{Materiales y métodos}

El trabajo de campo se hizo en la Reserva Natural (RN) Las Unamas, adscrita a la Asociación Red de Reservas Naturales de la Sociedad Civil, Nodo Orinoquia, entre los años 2006 - 2007. Fue coordinado por la Fundación Horizonte Verde en el Departamento del Meta (Figura 1). La Reserva está ubicada en la vereda la Novilla, a $30 \mathrm{~km}$ del casco urbano del municipio de San Martín, departamento del Meta. El área se encuentra clasificada como cálido húmedo a muy húmedo tropical, según el sistema Köppen. La altitud es de 300 msnm; la humedad relativa del $80 \%$ al $90 \%$ y la temperatura promedio de $27^{\circ} \mathrm{C}$. La Reserva cuenta con 1.450 ha, de las cuales 900 presentan bosque de galería con presencia de palma de seje.

\section{Caracterización florística y suelo}

La caracterización florística y estructural del área de estudio se realizó con la metodología para el levantamiento de información de biodiversidad vegetal de Cormacarena (2002), en tres bosques de la Reserva Natural. Camoa, Chumeco y Porongo. Cada uno fue 


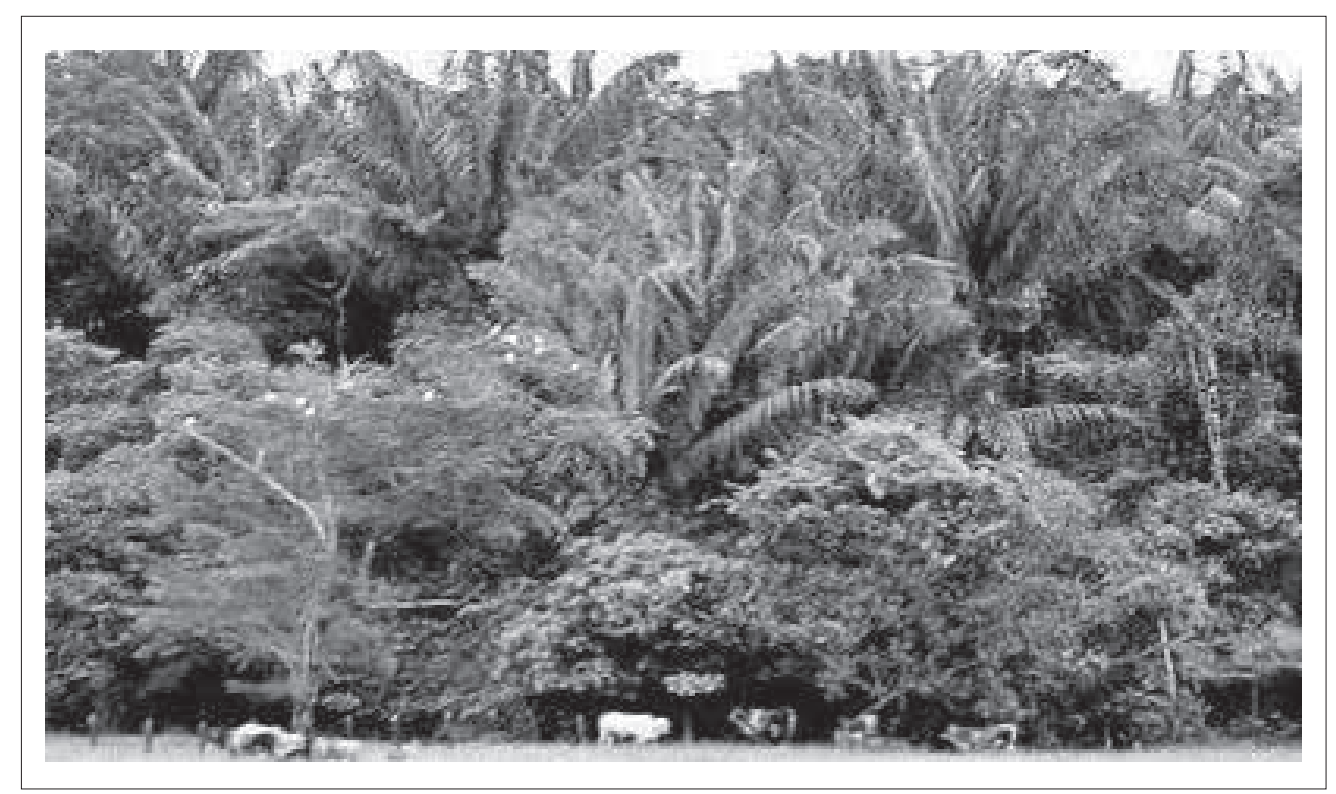

Figura 1. Reserva Natural Las Unamas, bosques de galería con palma de seje

dividido en transectos de 2 hectáreas y subdivididos en 3 parcelas de $100 \mathrm{~m} \times 10 \mathrm{~m}\left(1.000 \mathrm{~m}^{2}\right)$, para medición del número de palmas. En cada parcela se inventarió el 100\% para fustales individuos con diámetro a la altura del pecho $(\mathrm{DAP}>10 \mathrm{~cm})$ y latizales; para los brinzales (DAP $<10 \mathrm{~cm}$ ) se trabajaron 2 sub-parcelas de $2 \times 2 \mathrm{~m}$ al interior de cada parcela. Se determinó el estado productivo de las palmas. Una palma productiva de determinó por la presencia de estructuras reproductivas como ráquis, botón floral o bráctea peduncular leñosa, inflorescencias fecundadas, inflorescencias sin fecundar, frutos maduros, frutos inmaduros y brácteas cerradas. Las palmas improductivas fueron aquellas sin estructuras reproductivas y sin señales de haber ocurrido un proceso reproductivo.

En todas las parcelas se colectaron muestras y se llevaron al herbario de la Universidad de los Llanos. Se tomaron 3 muestras de suelo por cada parcela, para un total de 12 muestras, realizando cajuelas de $20 \times 20 \times 20$ $\mathrm{cm}$. El suelo se mezclo y de allí se tomaron $2 \mathrm{~kg}$ para analizar los macro y micro minerales en el Laboratorio de Suelos de la Universidad de los Llanos.

\section{Extracción de Aceite de Seje}

El proyecto de investigación valoró el método de extracción de aceite de seje, evaluando un protocolo artesanal o tradicional - protocolo 1 (Figuras 2 y 3 ) y puso a prueba dos protocolos de extracción con manejo de la temperatura, con el objetivo de mejorar el porcentaje de extracción de aceite, sin someter el proceso a solventes químicos u otro método que alterase la producción limpia del producto obtenido a partir de los frutos de las palmas del bosque. En el protocolo 2 , el proceso de ablandamiento del fruto se realizó a $45^{\circ} \mathrm{C}$. Se dejó a la espera durante 24 horas y luego se despulpó a la misma temperatura. El jugo obtenido se cocinó con el residuo llamado "Unche" (Figura 4). En el protocolo 3 se trabajó la extracción de aceite del residuo mediante prensado con tornillo sin fin. Este protocolo fue descartado por ruptura en dos ocasiones del tornillo sin fin durante el prensado del residuo o unche. Se evaluó la extracción del aceite utilizando frutos cercanos a su punto final de maduración (pintones) y maduros.

Se determinó la composición de los ácidos grasos del aceite de seje con la técnica de cromatografía de gases, y se hizo un análisis de la composición nutricional de la torta resultante, luego de la extracción del aceite.

\section{Resultados}

\section{Estado productivo de la palma de seje (Oenocarpus bataua Mart.)}

El número de palmas por hectárea fue determinado para los tres bosques: Camoa, Chumeco y Porongo. Los dos primeros se destacaron por la abundancia de palmas adultas con diversidad media-alta de Oenocarpus bataua Mart. En el bosque Camoa se observó elementos característicos del bosque primario de los Llanos. El número de palmas promedio en los tres bosques fueron de 187,7 palmas ha ${ }^{-1}$, de las cuales el $67 \%$ 
correspondieron a palmas productivas $(125,7$ palmas ha $^{-1}$ ) y el $33 \%$ a palmas improductivas (62 palmas ha 1). La mayor población de palma se encontró en el bosque Chumeco, con 283 palmas ha ${ }^{-1}$, seguida por el bosque Camoa, con 145 palmas ha ${ }^{-1}$ y en el tercer lugar el bosque Porongo, con 135 palmas ha-1.

\section{Composición de los bosques y calidad de suelos}

Los bosques estudiados corresponden a bosques primarios del Piedemonte y hacen parte de los últimos relictos de bosques de este tipo en la región de la Orinoquia. Su riqueza fue corroborada por los inventarios realizados en el proceso de caracterización, identificando 81 familias de plantas con 248 géneros y 446 especies de plantas. Es posible que la gran diversidad reportada se deba a la confluencia de elementos propios de los bosques andinos, de las sabanas del piedemonte, de la altillanura en transición al piedemonte y en gran medida de los bosques amazónicos.

La Figura 2, ilustra las familias con mayor número de especies en el bosque de galería de la Reserva Natural Las Unamas. El bosque Camoa se observó e identificó como relicto de bosque primario, con una extensión aproximada de 500 ha. Este bosque unía anteriormente los bosques andinos con los bosques de la llanura aluvial del río Meta, los cuales se encuentra distribuidos generalmente en áreas planas y en las áreas de mayores pendientes de la Reserva Natural. En él se destaca la abundancia de palmas adultas de dosel como: unama (Oenocarpus bataua Mart.), cumare (Astrocaryum chambira Burret), corneto (Iriartea deltoidea Ruiz \& Pav.), chuapo (Socratea exorrhiza Mart. H. Wendl.), cucurita (Attalea maripa Aubl. Mart.) y manaca (Euterpe predatoria Martius). En el sotobosque se observaron palmas como corozo de zaino (Astrocaryum gynacanthum Mart.), molinillo (Geonoma deversa Poit. Kunth. y G. Longepedunculata Burret.), San Pablo (Genoma interrupta Ruiz \& Pav. Mart.), cubarro (Bactris brongniartii Mart.), cubarro (Bactris maraja), pusuy (Oeno-

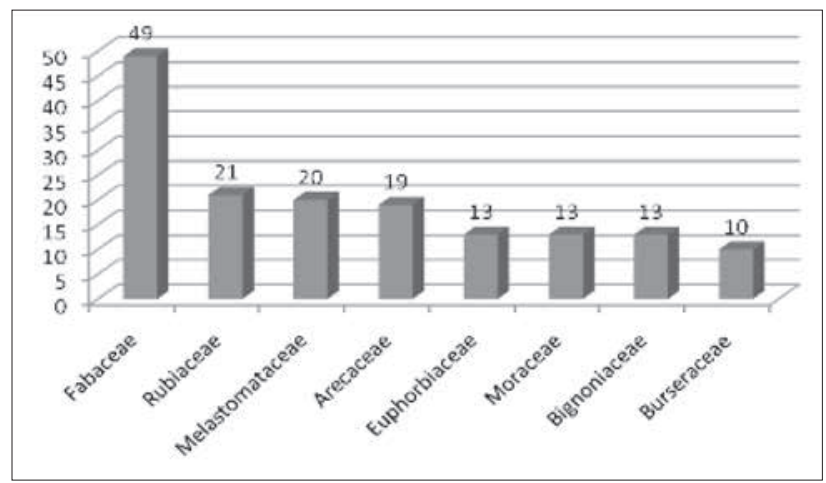

Figura 2. Familias con mayor número de especies en la RN Las Unamas. carpus minor Mart.), churruguay (Syagrus orinocensis Spruce Burret.) y yagua (Attalea insignis Mart. Drude.), cuya presencia evidencia un buen estado de desarrollo y conservación del bosque.

El bosque Chumeco, con una extensión de 200 ha, presentó una composición florística con elementos característicos de bosque primario, con especies arbóreas de alto diámetro y altura, como el avichure (Couma macrocarpa Bar. Rodri.), chuapo (Socratea exorrhiza Mart. H. Wendl.), cachicamo (Calophyllum brasiliensis Camb.), yapí (Pseudolmedia laevis R.\&P. Macbr.), yapí Amarillo (Pseudolmedia oblicua Karsten Renner), churruguay (Syagrus orinocense), cubarro (Bactris maraja Mart.), charo (Brosimum lactescens S. Moore. C.C. Berg.) y el guamo loro (Inga cylindrica Well. Mart.), entre otras. El sotobosque evidencio una presencia media de lianas y epifitas como falso caucho (Souroubea guianensis Aubl.), falso caucho (Norantea guianensis Aubl.), barbasco falso (Derris pterocarpus DC. Killip), clitoria (Clitoria javitensis Kunth Benth), bejuco cuadrado (Pleonotoma jasminifolia Kunth Miers), bejuco (Arrabidaea candicans Rich DC.), bejuco (Dichapetalum spruceanum Baill.), balazo (Monstera gracilis Engl.), balazo (Monstera adansonii Schott) y anturio macho (Philodendron fragantissimum Hook G. Don).

La flora hallada en el bosque Porongo correspondió a bosques de galería típicos que acompañan el recorrido de dos caños en la Reserva Natural, con un área aproximada de 200 ha. Son bosques relativamente uniformes, con presencia de muchos individuos de especies no dominantes; chuapo (Socratea exorrhiza Mart. H. Wendl.), cachicamo (Calophyllum brasiliensis Camb.), higuerón (Ficus insipida Willd.), matapalo (Ficus spp.) y charo (Brosimum latescens S.Moore C.C. Berg). EI sotobosque presentó poca densidad, con presencia de lianas y epifitas. En su mayoría alberga individuos de especies como el tuno (Miconia affinis DC.), Pariana $s p$, mapurito (Casearia javitensis Kunth.), lengua vaca (Monotagma laxum Poepp. \& Endl. Schum.), molinillo (Geonoma deversa), chuapo (Socratea exorrhiza Mart. H. Wendl.), guamo (Inga alba Sw. Willd.) y carne vaca (Virola sebifera Aubl.).

La Figura 3, ilustra la distribución de especies dominantes de los bosques de galería de la Reserva Natural Las Unamas. Especies como Oenocarpus bataua Mart., Virola sebifera Aubl. e Iryanthera laveis Markgr. fueron las de mayor prevalencia en todos los bosques, pero en mayor cantidad en los de Camoa y Chumeco. En el bosque Porongo se encontró en mayor cantidad Socratea exorrhiza Mart. H. Wendl., Iryanthera laveis Markgr. y Protium crassipetalum Cuatrec. Los bosques Chumeco y Porongo tuvieron una composición florísti- 


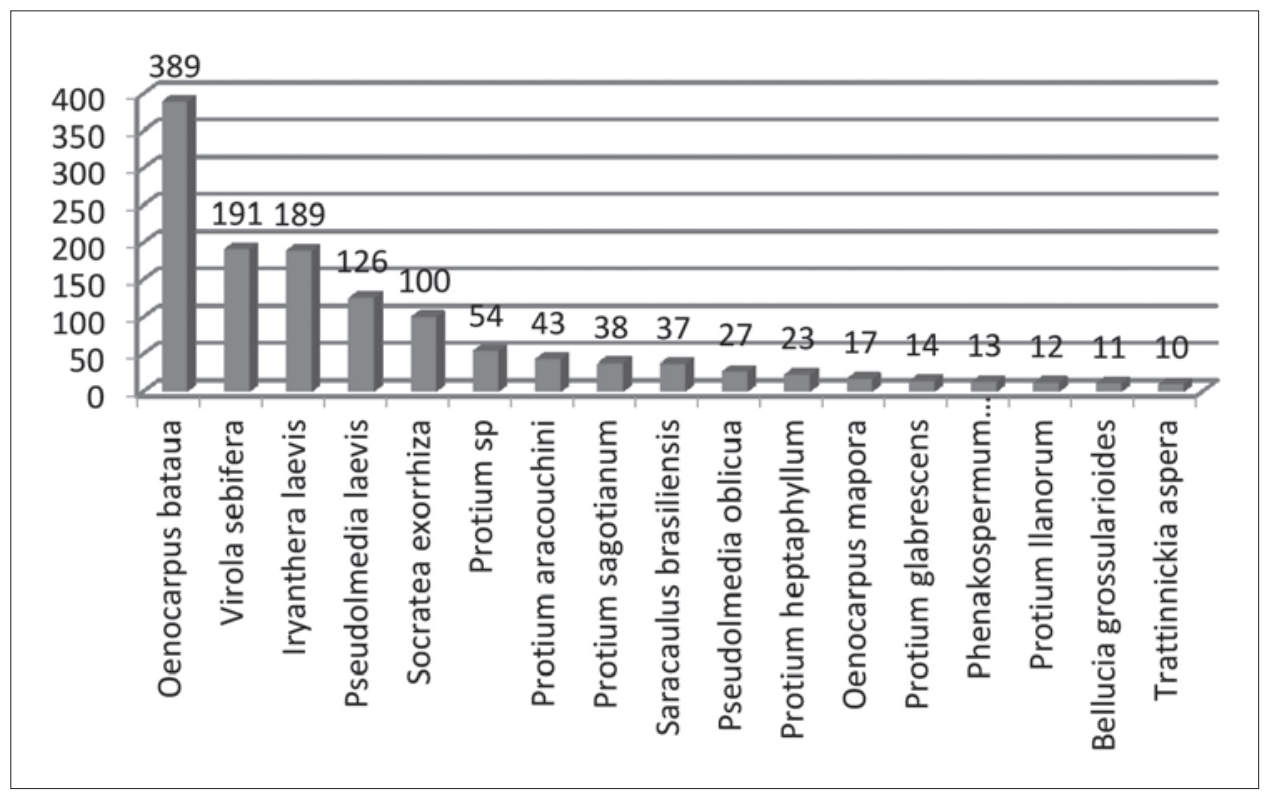

Figura 3. Distribución de especies dominantes de los bosques de galería

ca de amplia variedad de especies raras o pocos abundantes, destacándose especies del sotobosque con presencia de elementos amazónicos.

La Tabla 1, presenta los promedios de la composición química del suelo para los tres bosques estudiados. La calidad de los suelos encontrados en estos bosques describe condiciones de suelos de baja fertilidad, muy bien drenados, de textura predominante Franco-Arenosa y Arenoso-Franca, con menor presencia de Franco-Arcillosas y Franco-Arcillo-Arenosas. Presentan bajos contenidos de bases ( $\mathrm{Ca}, \mathrm{Mg}, \mathrm{K}$ y Na), baja disponibilidad de Fósforo y elementos menores $(\mathrm{Mn}, \mathrm{Zn}$, $B$ y S), pero elevadas concentraciones de elementos como Fe y Al, que sugieren una baja capacidad de intercambio catatónico.

\section{Cosecha de la palma de seje y protocolos de extracción de aceite}

La evaluación productiva de la palma de seje se determinó utilizando 36 palmas al azar, con frutos maduros o en proceso final de maduración. La producción promedio por palma fue de 2 racimos, con peso de 22.5 $\mathrm{kg}$, peso promedio de frutos de $14.5 \mathrm{~kg}$, con presencia de $500 \mathrm{~g}$ en frutos secos $y / 0$ verdes, un peso del raquis de $7.5 \mathrm{~kg}$ y 500 frutos por racimo.

El fruto analizado es oblongo o elipsoide, de 2.5 a 3.5 $\mathrm{cm}$ de largo y 2.0 a $2.5 \mathrm{~cm}$ de diámetro, con epicarpio (cáscara) liso, color rojo oscuro o violeta oscuro en la madurez. El mesocarpio del fruto es carnoso y blanquecino, fracción que contiene el aceite. La semiIla está recubierta por fibras delgadas con endocarpio duro y con peso entre 5 y $14 \mathrm{~g}$, con un grosor de mesocarpio y epicarpio de 1 a $2 \mathrm{~mm}$.

En el departamento del Meta, la palma de seje tiene su mayor producción en los meses de mayo a agosto, sin embargo, todo el año se pueden encontrar racimos dispersos dentro del bosque. La cosecha, proceso y extracción del aceite de seje se inicia con la búsqueda de racimos con frutos maduros, que se encuentran a más de $6 \mathrm{~m}$ de altura, en bosques densos y con poca luz, cubiertos en su mayoría por líquenes que dificultan aún más reconocer el color. Los racimos maduros se cortan con cuchillo malayo (tubo desplegable en cuyo extremo se encuentra fija una

Tabla 1. Resultado promedio de los análisis de suelos en bosques de galería de la Reserva Natural Las Unamas.

\begin{tabular}{ccccccccccccccc}
\hline \multirow{2}{*}{$\begin{array}{c}\text { MO } \\
(\%)\end{array}$} & $\begin{array}{c}\mathbf{P} \\
(\mathbf{p p m}))\end{array}$ & $\mathbf{p H}$ & \multicolumn{4}{c}{ Cationes $(\mathbf{m e q} / \mathbf{1 0 0 g})$} & \multicolumn{4}{c}{ Cationes (ppm) } \\
\cline { 5 - 14 } & & Al & $\mathbf{C a}$ & $\mathbf{M g}$ & $\mathbf{K}$ & $\mathbf{N a}$ & $\mathbf{C u}$ & $\mathbf{F e}$ & $\mathbf{M n}$ & $\mathbf{Z n}$ & $\mathbf{B}$ & $\mathbf{S}$ \\
\hline 2.06 & 2.2 & 4 & 3.9 & 0.05 & 0.05 & 0.09 & 0.05 & 0.62 & 179 & 2.8 & 0.27 & 0.13 & 7.16 \\
\hline
\end{tabular}


cuchilla en forma de media luna, que se engancha en el racimo para hacer su corte). Se desgranan del raquis y se guardan en lonas que son llevadas por los cosechadores a espaldas, por el bosque. El fruto se lava y limpia de impurezas para iniciar el proceso de ablandamiento, a una temperatura de $50^{\circ} \mathrm{C}$. Luego se efectúa la maceración, se separa la semilla, se lava y el jugo obtenido se lleva a cocción hasta que por densidad aflora el aceite, flota en la superficie y se recolecta, se enfría y se filtra con papel antes del envasado (Ver figura 4). Este proceso fue considerado como artesanal, protocolo 1, usado por la Reserva Natural durante los 3 años anteriores al inicio de este proyecto, para la extracción de aceite de seje. Fueron realizadas seis pruebas de extracción:

\section{1) Protocolo 1 o Tradicional (Figura 5).}

Pruebas 1 y 2: La prueba 1 fue con fruto fresco (fruto procesado después del ablandamiento) y cocinada con unche (material resultante luego de la maceración del fruto y su lavado) y la segunda con fruto ablandado en agua durante 24 horas y cocinada sin unche.

\section{2) Protocolo 2 (Figura 6)}

Pruebas 3 y 4: La prueba 3 fue con fruto fresco (fruto usado después del ablandamiento) y cocinada con unche. La prueba 4 fue con fruto ablandado durante 24 horas y cocinada sin unche. Se manejó la temperatura de forma constante hasta la extracción del aceite, siendo este el principal factor de diferenciación con el método tradicional (aproximadamente $90^{\circ} \mathrm{C}$ ). Al inicio se probó con el uso de una marmita industrial para la cocción del jugo de Seje, pero esta idea se descartó por el alto consumo de combustible (gas propano), el cual es costoso y difícil de conseguir por la distancia de la Reserva Natural a la población urbana del municipio.

- Prueba 5, se evaluó el efecto de la temperatura en el inicio de la cocción del fruto. En esta experiencia se utilizó el agua caliente (aprox. $60^{\circ} \mathrm{C}$ ) al momento de iniciar la cocción del fruto (contrario a calentar el agua con el fruto hasta lograr $\operatorname{los} 45^{\circ} \mathrm{C}$ ), como se maneja en el método tradicional. Este manejo de la temperatura generó un endurecimiento extremo del fruto haciendo imposible la extracción del aceite.

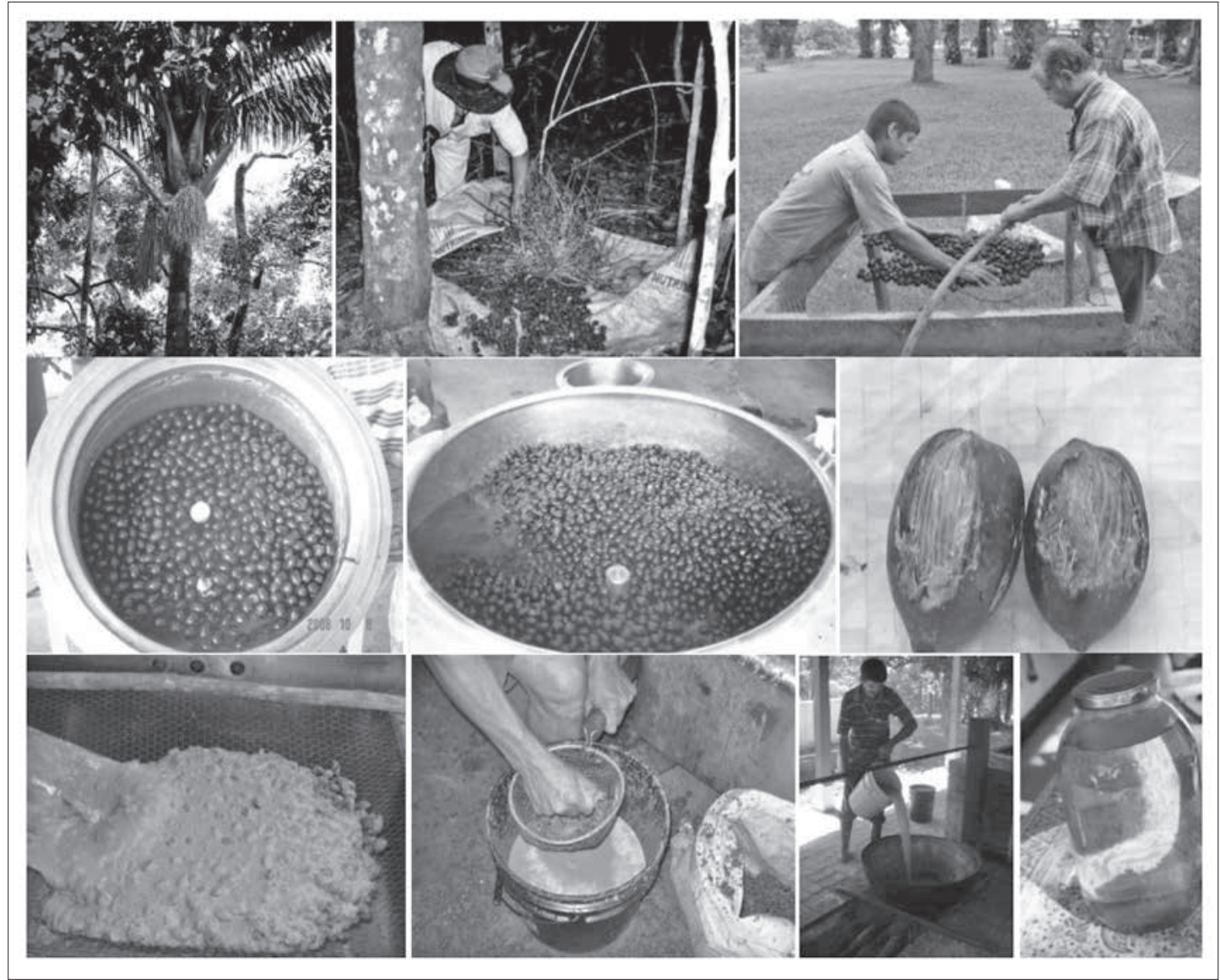

Figura 4. Proceso de extracción de aceite de seje (primera línea, cosecha y lavado de fruta de seje; segunda línea, cocción de la fruta y fruta en proceso de despulpado; tercera línea, salida de fruta del despulpado, separación del "unche", proceso de separación por calor y aceite de seje). 


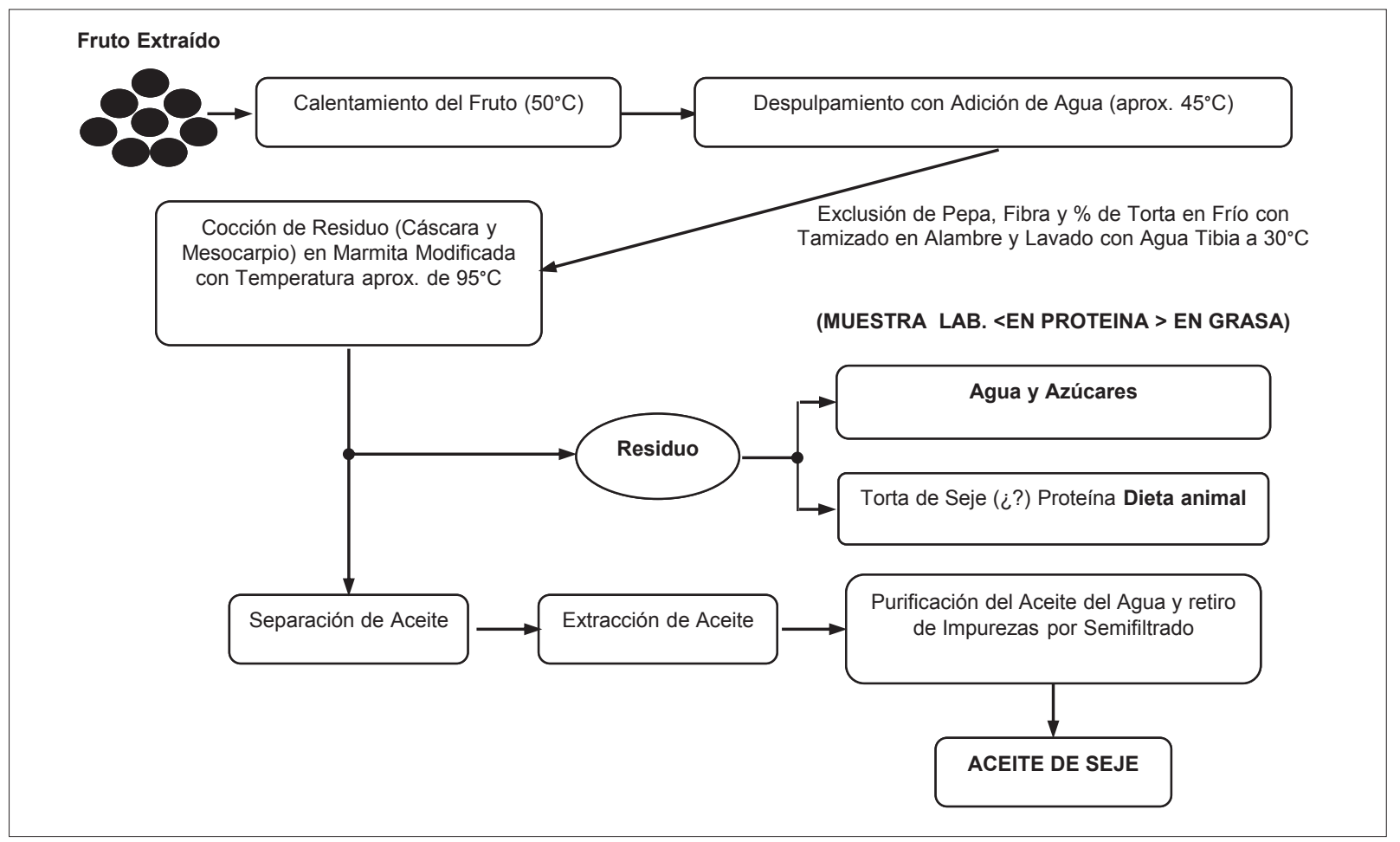

Figura 5. Protocolo 1 empleado en La Reserva Natural Las Unamas para extracción de aceite de seje

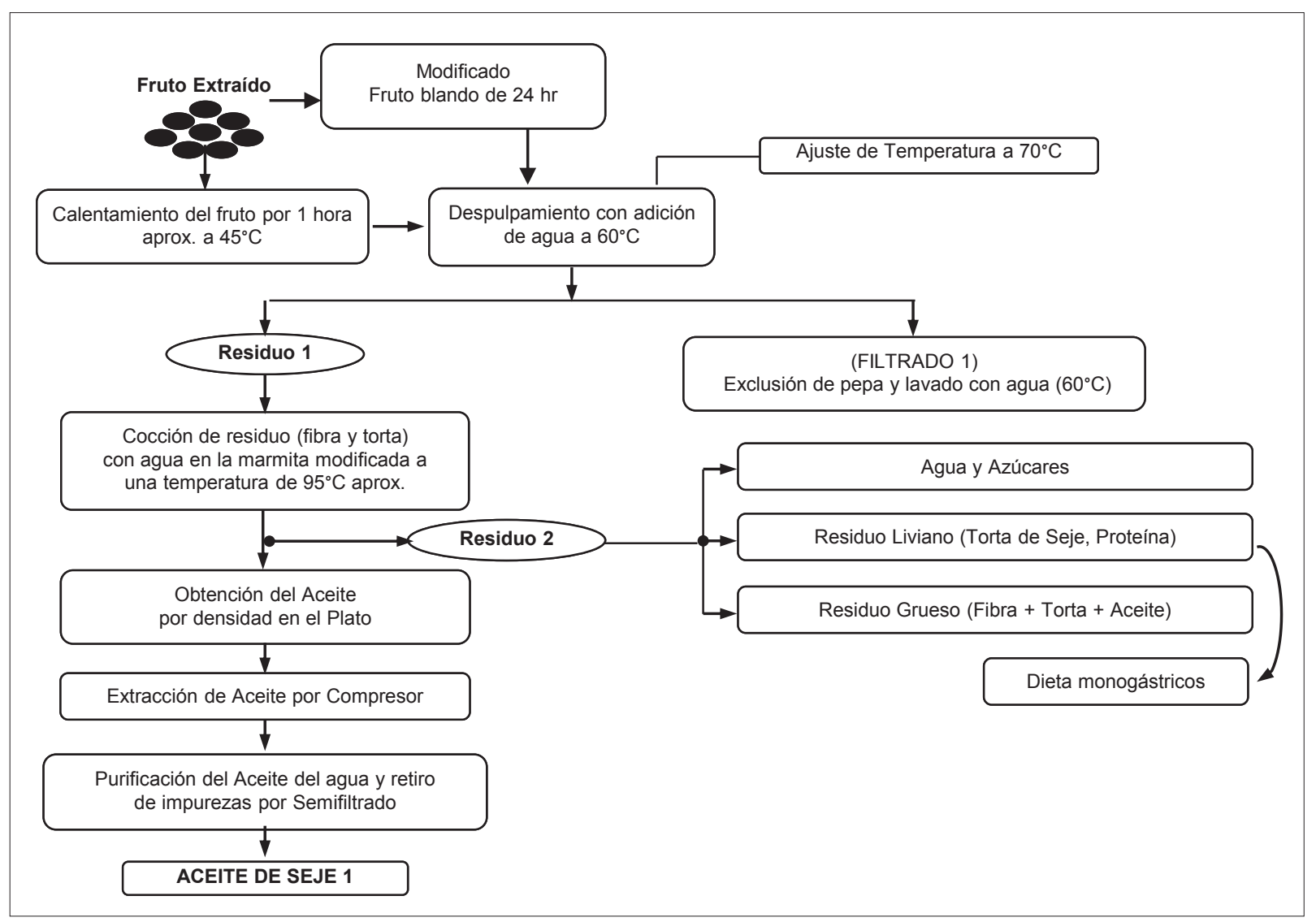

Figura 6. Protocolo experimental 2 para la extracción de aceite de seje 
En el proceso de extracción del aceite de seje, con el protocolo 1 tradicional, se obtuvo una extracción máxima de 2,5\% (prueba 2). El mayor porcentaje de extracción fue obtenido con el protocolo 2, donde se logró una extracción de aceite de 4,26\% (prueba 4), incrementando la extracción respecto al sistema tradicional en $70 \%$ (Tabla 2).

La torta de seje resultante del proceso de extracción fue analizada para determinar su calidad nutricional (Tabla 3). La torta de seje del protocolo 1 presentó mayor contenido de aceite $(6,1$ a $13,5 \%)$, mientras que el menor contenido de aceite fue obtenido en la torta del protocolo 2 (2,7 a 3,8\%). El contenido de proteína de la torta del protocolo 2 fue de $5 \%$, mientras que la torta del protocolo 1 tradicional oscilo entre 4 y $6 \%$.
La composición de macro y microminerales de la torta de seje y su alto contenido de materia orgánica, puede constituirse en valiosa fuente de minerales para futuros usos en alimentación animal.

\section{Composición del aceite de seje}

Los análisis de la composición del aceite de seje no presentaron diferencia respecto al uso de fruto semi-maduro ("pintón") o maduro, aunque el rendimiento o extracción fue mayor en fruto maduro $(3.48 \pm 1.0)$ que en fruto semi-maduro $(2.35 \pm 1.0)$.

Como puede observarse en la Tabla 4, el ácido graso oleico representa la mayor proporción en el aceite de seje $(81 \%)$, seguido del palmítico $(12 \%)$, esteárico (4\%) y los ácidos grasos esenciales linoléico $(2,5 \%)$ y

Tabla 2. Resultados de la extracción de aciete de seje según los protocolos experimentales

\begin{tabular}{|c|c|c|c|c|c|}
\hline \multirow{2}{*}{ Variables medidas } & \multicolumn{2}{|c|}{ Protocolo 1 Tradicional } & \multicolumn{3}{|c|}{ Protocolo 2} \\
\hline & Prueba 1 & Prueba 2 & Prueba 3 & Prueba 4 & Prueba 5 \\
\hline Peso Racimo (kg) & 43 & 28 & 29 & 28.5 & 34 \\
\hline Peso Raquis (kg) & 7 & 4 & 5 & 6.2 & 5 \\
\hline Peso Frutos (kg) & 36 & 24 & 24 & 22.3 & 29 \\
\hline Tiempo Fruto blando (horas) & 1 & 24 & 1 & 24 & --- \\
\hline $\mathrm{T}^{\circ}$ agua ablandamiento $\left({ }^{\circ} \mathrm{C}\right)$ & 45 & 45 & 45 & 45 & 60 \\
\hline Cocción & unche & sin unche & unche & sin unche & No ablando \\
\hline $\mathrm{T}^{\circ}$ despulpado $\left({ }^{\circ} \mathrm{C}\right)$ & 75 & 75 & 75 & 75 & - \\
\hline $\mathrm{T}^{\circ}$ cocción del jugo $\left({ }^{\circ} \mathrm{C}\right)$ & 90 & 90 & 90 & 90 & - \\
\hline Peso residuo Unche liviano, $g$ & 170 & 220 & 170 & 248 & - \\
\hline Aceite Extraído $(\mathrm{ml})$ & 800 & 600 & 500 & 950 & \\
\hline Aceite de Seje & Turbio & Traslucido & Opaco & Traslucido & - \\
\hline$\%$ de Aceite Extraído & 1.86 & 2.5 & 2.08 & 4.26 & - \\
\hline
\end{tabular}

Tabla 3. Análisis de la composición nutricional de la torta de seje según protocolo de extracción

\begin{tabular}{lcccc}
\hline \multirow{2}{*}{ DETERMINACIÓN \% } & \multicolumn{2}{c}{ Protocolo $\mathbf{1}$ tradicional } & \multicolumn{2}{c}{ Protocolo 2 } \\
\cline { 2 - 5 } & Muestra $\mathbf{1}$ & Muestra $\mathbf{2}$ & Muestra $\mathbf{3}$ & Muestra 4 \\
\hline Estado del fruto despulpado & Fresco & 24 horas & Fresco & 24 horas \\
Humedad Inicial & 48.72 & 30.77 & 64.29 & 60 \\
Humedad Final & 9.39 & 1.78 & 1.3 & 1.74 \\
Cenizas & 1.20 & 2.32 & 1.29 & 1.43 \\
Proteína & 4.02 & 6.3 & 5.42 & 5.25 \\
Grasa & $\mathbf{6 . 1 9}$ & $\mathbf{1 3 . 5 6}$ & $\mathbf{3 . 8 3}$ & $\mathbf{2 . 7 5}$ \\
Fibra Cruda & $\mathbf{3 9 . 1}$ & $\mathbf{2 5 . 6 4}$ & $\mathbf{3 3 . 3 9}$ & $\mathbf{3 7 . 7 5}$ \\
ENN (Calculado) & $\mathbf{4 0 . 1}$ & $\mathbf{5 0 . 4}$ & $\mathbf{5 4 . 7 7}$ & $\mathbf{5 1 . 0 8}$ \\
NDT (Calculado) & 60.12 & 80.09 & 65.18 & 66.16 \\
EB (Calculado) & 3.88 & 4.51 & 2.87 & 2.91 \\
ED (Calculado) & 2.65 & 3.53 & 4.08 & 4.01 \\
EM (Calculado) & 2.17 & 2.89 & 2.35 & 2.37 \\
\hline
\end{tabular}

Aceite de la palma de seje Oenocarpus bataua Mart. por su calidad nutricional puede contribuir a la conservación y uso sostenible de los bosques de galería en la Orinoquia Colombiana 
Tabla 4. Composición del aceite de seje para el estudio, otros valores de referencia y composición del aceite de oliva

\begin{tabular}{|c|c|c|c|c|c|c|c|}
\hline \multicolumn{2}{|c|}{ ÁCIDOS GRASOS } & \multicolumn{5}{|c|}{ ACEITE DE PALMA DE SEJE } & \multirow{2}{*}{$\begin{array}{c}\text { ACEITE OLIVA } \\
\text { Balick } 1998\end{array}$} \\
\hline $\mathbf{N}^{\circ}$ & Acido Graso & Estudio 2007 & FAO 2001 & Balick 1993 & $\begin{array}{c}\text { Estudio } \\
\text { Reserva } 2006\end{array}$ & Pedersen 2000 & \\
\hline 12:0 & Lauríco & & --- & --- & $0.14 \pm 0.5$ & 6.6 & --- \\
\hline 14:0 & Mirístico & $0.29 \pm 0.9$ & --- & 1.0 & $0.08 \pm 1.0$ & 2.5 & --- \\
\hline 16: 0 & Palmítico & $12.80 \pm 1.0$ & 8.8 & $8.8-13.2$ & $13.77 \pm 0.2$ & 13.7 & $9.4-11.2$ \\
\hline $16: 1$ & Palmitoleico & $0.84 \pm 0.2$ & --- & 0.6 & $1.26 \pm 0.5$ & 0.9 & $0.2-1.5$ \\
\hline $18: 0$ & Esteárico & $4.24 \pm 0.5$ & 5.6 & $3.6-5.6$ & $4.43 \pm 0.7$ & 3.0 & $1.4-2.0$ \\
\hline $18: 1$ & Oleico & $81.17 \pm 1.0$ & 76.5 & $76.5-77.7$ & $76.62 \pm 1.0$ & 69.2 & $76.0-80.5$ \\
\hline $18: 2$ & Linoleíco & $2.49 \pm 0.5$ & 3.4 & $2.7-3.4$ & $2.86 \pm 0.5$ & --- & $6.9-8.5$ \\
\hline $18: 3$ & Linolénico & $1.07 \pm 0.2$ & --- & 0.6 & $2.86 \pm 0.5$ & $2-4$ & $0.4-0.5$ \\
\hline$\%$ Insat & $77-82$ & $81.93 \pm 1.0$ & $68-78$ & $79.9-81.6$ & & 0.9 & $86.5-87.4$ \\
\hline$\%$ Sat & $2-4$ & $3.25 \pm 0.5$ & 3 & 2 & & 3.0 & $7-8$ \\
\hline
\end{tabular}

Insat: Ácidos Grasos insaturados Sat: Ácidos Grasos Saturados

linolénico (1\%). La presencia de ácido oleico resulto mayor que la reportada para el aceite de oliva y comparada con otros reportes de aceite de seje (ver Tabla 5). Sin embargo, puede afirmarse que los aceites de oliva y seje tienen una composición que presenta una proporcionalidad muy similar en sus ácidos grasos.

\section{Discusión}

\section{Estado productivo de la palma de seje (Oenocarpus bataua Mart.)}

Se encontró una población alta de palmas jóvenes y palmas adultas en producción de la especie Oenocarpus bataua Mart. (187 palmas ha-1), población intermedia a la reportada por Cifuentes et al. (2010), quienes para un "milpesal" puro encontraron 278 palmas ha $^{-1}$ y para uno mezclado "marrupal mixto" 82 palmas ha1. Las palmas productivas encontradas en este estudio fue del $67 \%$, ligeramente superior a otras investigaciones que registraron 60\% (Cifuentes et al. 2010).

La densidad de palmas registrada sugiere que la dinámica ecológica de la especie y su adaptación a los suelos característicos de esta zona de transición andina-orinocense y amazónica, han permitido una presencia dominante de la palma de seje en los bosques de galería estudiados (Figura 4), favorecida además por la baja intervención antrópica en los bosques de la Reserva Natural Las Unamas.

\section{Composición de los Bosques y calidad de suelos}

La familia Fabaceae registró el mayor número de especies (49), duplicando a la familia Rubiaceae (21), se- gunda en los registros de esta investigación. Comportamiento que confirma lo señalado por Gentry (1988), quien describió a la familia Fabaceae como la más diversa en los bosques neotropicales. En los distintos bosques de la Orinoquia y Amazonia colombiana, las Fabaceae aparecen como la familia de mayor importancia (Díaz et al., 2006).

Especies como Oenocarpus bataua Mart., Virola sebifera Aubl. e Iryanthera laveis Markgr. Fueron las de mayor abundancia en todos los bosques (aunque mayor cantidad en los bosques Camoa y Chumeco), coincidiendo con otros reportes que consideran a Oenocarpus bataua Mart. como una de las especies con mayor presencia en los bosques neotropicales (Galeano y Bernal, 1987; Kahn 1991; Balick, 1992; Henderson et al., 1995). Los resultados para las clases diamétricas en los tres bosques estudiados, evidencian que existe un proceso de regeneración sostenida por ejemplares de bosque primario bien conservado, con DAP de $\geq$ $30 \mathrm{~cm}$. En el bosque Porongo se encontró en mayor cantidad Socratea exorrhiza Mart. H. Wendl., Iryanthera laveis Markgr. y Protium crassipetalum (Figura 6). Los bosques estudiados tuvieron una composición florística de amplia variedad de especies raras o poco abundantes, destacándose especies del sotobosque con presencia de elementos amazónicos. Este estado de sucesión primaria, puede estar influenciado por las características fisonómicas del terreno, la dinámica de los ciclos climáticos, la historia natural de algunas especies y la calidad de los suelos (Romero et al. 2004).

Respecto a los suelos, la calidad físico-química encontrada en estos bosques y la presencia de Oenocarpus bataua Mart., sugiere que la palma de seje puede ser considerada como una especie promisoria por su espe- 
cial adaptación a suelos considerados pobres (Galeano y Bernal, 1987, 2010; Cifuentes et al. 2010; Balick, 1992; Morcote-Ríos et al., 1998).

Según Romero et al., (2004), estos suelos del piedemonte antiguo tectonizado de sabanas y bosques, con precipitaciones fuertes estacionales y períodos marcados de sequía, muy frágiles y limitados para uso en la agricultura permanente y la actividad agropecuaria se caracterizan por tener: a) escasez de nutrientes disponibles, esenciales para los cultivos; b) deficiencia en materia orgánica; c) elementos tóxicos para algunas plantas (hierro, manganeso y aluminio); d) relieve disectado y presencia de capas endurecidas y cementadas por hierro y e) susceptibilidad a la erosión por escorrentía, erosión eólica y por movimientos en masa. Adicionalmente, estos suelos Oxisoles y Ultisoles están caracterizados por su alta acidez y baja fertilidad natural, y se constituyen en los suelos predominantes de la cuenca del Orinoco y la región Amazónica (Cuevas, 2001). Allí el fósforo es, con frecuencia, el elemento limitante de la fertilidad (Pérez et al., 2007). Su presencia se debe casi exclusivamente, a la descomposición de la materia orgánica. El acceso de las plantas a los fosfatos es limitado y depende en gran medida de las características de su sistema radicular y complejas relaciones con microorganismos, el cual determina la eficiencia en la exploración y absorción del fósforo.

Entonces, es de gran importancia evaluar la capacidad productiva de este tipo de bosques, que tienen poblaciones importantes de palma de seje. El sistema radicular de esta palma está conformado por raíces adventicias que se desplazan lateralmente a una distancia de más de siete metros (Borgtoft-Pedersen \& Balslev, 1993). Aquello favorece la extracción de elementos como el fósforo y otros minerales indispensables para la producción de la palma. En plantas con un sistema radical poco desarrollado, esta limitación puede ser superada si se establece una simbiosis con hongos formadores de micorrizas (Salamanca et al., 2004; Martínez et al., 2009; Rodríguez-Echeverría, 2009).

Es factible que la capacidad productiva de estos bosques con palma de seje pueda explicarse por una actividad orgánica en la superficie el suelo, de la hojarasca (mulch), que tiene su mayor actividad en el perfil A del suelo. Ello genera una oferta de nutrientes al sistema radicular de la palma. La simbiosis entre microorganismos y plantas en el "mulch" da vida a los suelos en los bosques, ofrece una diversidad de hongos, esporas, bacterias e hifas que ayudan a la descomposición del material orgánico como brácteas, hojas de palmas y elementos de alto contenido de lignina. Esto permite a las plantas una forma segura de adquirir y diversificar nutrientes como $\mathrm{N}, \mathrm{K}, \mathrm{Ca}, \mathrm{Mg}, \mathrm{Fe}, \mathrm{Mn}$ (Johansen et al., 1994; Salamanca, 2004), obtener agua y extender el área radical que facilita su capacidad de sostenerse físicamente en el suelo, mejora su resistencia y adaptabilidad al ecosistema. Además de su efecto directo en la nutrición, también inducen a cambios fisiológicos que comprenden un aumento en la tasa fotosintética y redistribución del carbono fijado hacia las raíces, solubilización del fósforo y mecanismos de defensa contra patógenos de plantas (Salamanca, 2004; Rodríguez Echavarría, 2009).

Estos procesos orgánicos en la superficie del suelo ofrecen hongos, levaduras, hidratos de carbono (azucares, almidones, entre otros) y minerales como $\mathrm{Ca}$, $\mathrm{Mg}, \mathrm{Zn}, \mathrm{B}$ y $\mathrm{P}$ a los microorganismos, necesarios para su alimentación y provenientes de la fotosíntesis de la planta. Esta interacción ayuda a los bosques de la Orinoquia (Romero et al., 2004) limitando los efectos dañinos de la erosión causada por el agua, a su vez que el incremento en los procesos de absorción y translocación de nutrientes como $\mathrm{N}, \mathrm{P}, \mathrm{K}, \mathrm{Ca}, \mathrm{Mg}, \mathrm{S}, \mathrm{Zn}$, $\mathrm{Cu}, \mathrm{Mo}, \mathrm{Fe}, \mathrm{Mn}$; y la no absorción toxica de algunos de ellos. Factores como la acidez, las concentraciones de materia orgánica, $\mathrm{P}, \mathrm{N}, \mathrm{Al}, \mathrm{Cu}$ y $\mathrm{Zn}$ en el suelo, inciden sobre el buen establecimiento y desempeño de la simbiosis. Ello se refleja en la capacidad de colonización de hospederos y la producción de esporas e hifas de hongos (Sieverding, 1984; Bhatia et al., 1996; Sleverding, 1991; Van der Heijden et al., 2008) que fácilmente interactúan con especies como las palmas nativas de la zona. La composición físico-química del suelo de los bosques estudiados (ver Tabla 1), pobre en materia orgánica, muy ácida y con muy bajo contenido de nutrientes, pero alta contenido de aluminio y hierro, no permite explicar el comportamiento productivo de la palma de seje. Posiblemente la dinámica biológica expuesta sea el sustento de la productividad de la palma y el bosque.

Las palmas establecen relaciones ecológicas de una alta especialización, tanto en los sistemas reproductivos como en las interacciones con sus insectos polinizadores (Jelínek 1992, Ervik 1995, Küchmeister 1997, Küchmeister et al. 1998, Henderson 2002, Núñez et al. 2005). García M. (1988) sugiere que los principales polinizadores de la palma de seje o milpesos (O. bataua) son escarabajos de las familias Curculionidee (Phyllotrox spp. y Derelomini spp.) y Nitidulidae (Mystrops spp.). Cabe anotar que las inflorescencias son visitadas por gran cantidad de insectos, reportándose cerca de 80 insectos y arácnidos diferentes, con los escarabajos como los más abundantes (Balick 1992). 
La mutualidad simbiótica del bosque permite la producción de especies como la palma de seje, que a su vez es usada por la biodiversidad de fauna representada en mamíferos. Se reporta que sus frutos hacen parte de la dieta de zainos (Pecari tajacu Linnaeus), cajuches (Tayassu pecari Link), monos capuchinos (Cebus albifrons Humboldt, Sapajus apella Linnaeus) y el mono araña (Ateles belzebuth É. Geoffroy) (Zona \& Henderson; La Rotta 1989). También de aves como loros (Pionus fuscus Müller, Pionites melanocephalus Linnaeus, Amazona achrocephala Gmelin y Amazona farinosa Boddaert), tucanes (Rhamphastos tucanus) y la pava (Penelope marail Muller) (Sist \& Puig 1987, La Rotta 1983).

La palma de seje y su comportamiento productivo, es un buen ejemplo de la necesidad de considerar las dinámicas orgánicas en los suelos de la Orinoquia, en particular, los suelos de los bosques de galería, que según la información físico-química serían clasificados como de muy bajo potencial productivo y deberían ser transformados.

\section{Épocas de cosecha y protocolos de extracción de aceite}

Los parámetros productivos obtenidos en este estudio (2 racimos palma ${ }^{-1}$, peso de $22,5 \mathrm{~kg}$, de los cuales 14,5 $\mathrm{kg}$ son frutos, $500 \mathrm{~g}$ de frutos secos, $7,5 \mathrm{~kg}$ de raquis y 500 frutos por racimo) están entre los rangos reportados por otros autores como Balick (1982) y García (1997). Ellos reportaron 1,5 racimos palma ${ }^{-1}$, con peso aproximado de $28,6 \mathrm{~kg}$ y un promedio de peso en frutos de 19,2 kg, que pueden variar en el número de frutos desde 500 a 800 . Vallejo (2002) reporta entre 3-4 racimos palma ${ }^{-1}$, con más de 1.000 frutos cada uno. Ríos et al. (1997) afirman que, en un racimo, se pueden encontrar en promedio 1.362 frutos, con un peso aproximado de $19 \mathrm{Kg}$. En el pacífico colombiano Collazos \& Mejía (1988) observaron que un racimo produce como máximo 1.300 frutos y como mínimo 64 , con un peso promedio de 6,2 kg. Cifuentes et al. (2010) registró una producción de frutos maduros por ciclo de 34 meses, de $3.014 \mathrm{~kg}$ y $330 \mathrm{~kg} \mathrm{ha}^{-1}$ para bosques inundables del Chocó biogeográfico.

En este estudio, el porcentaje de extracción de aceite respecto al peso del fruto oscilo entre 2,5 (protocolo 1 tradicional) y 4,3 (protocolo 2) en condiciones de bosque de galería. Estos valores son inferiores a otros registrados para otros ecosistemas. Villachica (1996) afirma que de cada racimo puede obtenerse entre 5.2 y $6.4 \%$ de aceite. Blaak (1992) reporta un potencial de extracción entre 14 y $23 \%$ de aceite y otros como Balick et al. (1981) y Mejía (1988 y 1992) registran extracciones del $5 \%$ al $6 \%$, del epicarpio y mesocarpio del fruto, sin la utilización de solventes químicos en el proceso. Balick et al., (1981) y Balick (1982 y 1985) sugieren que el contenido de aceite en el mesocarpio esta alrededor de 19 al 23\%, y en el epicarpio del $14.5 \%$, por lo cual gran cantidad de aceite se queda en el jugo cocinado durante la extracción.

Aunque el contenido de grasa de la torta de seje se redujo entre los protocolos 1 tradicional (promedio de $9,8 \%$ ) y protocolo 2 (promedio de $3,2 \%$ ), es evidente que hay una fracción importante de aceite que no se logró extraer. Al parecer, cuando se está calentando el "unche" para extraer el aceite, debido al alto peso molecular, algunas lipoproteínas (especialmente las lipoproteínas alfa) se precipitan al elevarse la temperatura del agua (Harper, 2002). Asimismo, parece haber un efecto por la presencia de gomas o consolidados no conocidos, que reaccionan rápidamente al manejo de la temperatura, encapsulando el aceite e impidiendo su extracción. Además, la evidencia de los contenidos de fósforo en la torta de seje sugiere alta presencia de este elemento en los frutos. El fosforo podría impedir el desdoblamiento de los fosfolípidos no hidratables, durante el proceso de extracción. Esto resultaría en bajo porcentaje de aceite extraído.

No obstante lo anterior, la torta resultante de la extracción del aceite de seje puede considerarse como un alimento completo para alimentación animal, especialmente de monogástricos. Su contenido de grasa, proteína, ENN, macro y macrominerales permitirían su uso en alimentación de aves y cerdos.

\section{Composición del aceite de seje}

Podría decirse, como referente para aquellos poco familiarizados con palmas tropicales, que el aceite de seje tiene una composición equivalente al aceite de oliva. Ello permite afirmar que es adecuado para el consumo humano y, desde luego, con potencial de uso estratégico en la nutrición animal. La composición de ácidos grasos del aceite de seje presentó una mayor concentración de ácido oleico (81\%) comparado con otros reportes de literatura y respecto al aceite de oliva (Tabla 5). Los contenidos totales de ácidos grasos insaturados y saturados fueron para el aceite de seje similares al del aceite de oliva (Balick, 1993 - 1998; Pedersen, 2000; FAO, 2001; Estudio Reserva, 2006). Una determinación de la composición del aceite de seje hecha previamente en la Reserva Natural Las Unamas, presentó menor contenido de ácido oleico y mayor contenido de ácidos linoléico y linolénico que los obtenidos en este estudio. 
Tabla 5. Composición de macro y micronutrientes de la torta de seje

\begin{tabular}{|c|c|c|c|c|c|c|c|c|c|c|c|c|c|c|}
\hline \multirow{2}{*}{ Text. Tacto } & \multirow{2}{*}{ M.O (\%) } & \multirow{2}{*}{ P. Ppm } & \multirow{2}{*}{$\begin{array}{l}\mathrm{pH} \\
1: 1\end{array}$} & \multicolumn{5}{|c|}{ CATIONES meq/100 g M.O } & \multicolumn{6}{|c|}{ CATIONES (ppm) } \\
\hline & & & & Al & $\mathrm{Ca}$ & $\mathbf{M g}$ & K & $\mathrm{Na}$ & $\mathrm{Cu}$ & $\mathrm{Fe}$ & Mn & $\mathrm{Zn}$ & B & S \\
\hline M.O & 44.3 & 54.8 & 4.8 & 0 & 8.50 & 2.75 & 2.11 & 0.87 & 3.35 & 0.45 & 44.37 & 10.35 & 4.68 & 39.12 \\
\hline
\end{tabular}

Un cálculo estimado de producción de aceite de seje de estos bosque de galería, teniendo como referencia el porcentaje de extracción del protocolo 2 y una población de palmas productivas del $62 \%$, sugiere que se podría producir aproximadamente 150 litros de aceite ha- $\mathrm{año}^{-1}$. La producción podría llegar a 195.000 litros de aceite de seje año ${ }^{-1}$ para la zona de estudio, considerando un total de 1.300 ha de bosque. Un estimativo del valor de este aceite en el mercado, considerando su similitud al aceite de oliva, podría estar alrededor de \$3 USD litro $^{-1}$ de aceite, lo cual significaría un valor neto de $\$ 600.000$ USD. Esto sugiere que existe un gran potencial productivo para un uso sostenible del bosque, mediante la extracción racional de aceite de seje. Como parte de la búsqueda de oportunidades de mercado para el aceite de seje, se diseñaron botellas de vidrio fabricadas a mano con su respectiva etiqueta, relacionando el aceite con la conservación del bosque y su calidad nutricional - Conservando el Bosque Productivo (Figura 7). No obstante, deben considerarse evidencias de la estacionalidad de la producción de la palma de seje. Cifuentes et al. (2010) encontró que la producción de frutos maduros en el Chocó biogeográfico ocurre cada 34 meses (22 meses de producción alternada con 12 meses de oferta nula), con un estimado de 192 racimos ha $^{-1}$, proyectando una producción de frutos maduros $3014 \mathrm{~kg} \mathrm{ha}^{-1}$ por ciclo productivo.
La perspectiva económica del aceite de seje permitiría una más eficiente conservación de los bosques de galería de la zona en estudio y de la Orinoquia en general.

\section{Conclusiones}

La palma de seje Oenocarpus bataua Mart. es un ejemplo de plantas útiles en los bosques de galería orinocenses, utilizada ancestralmente por los pobladores nativos, adaptada a las condiciones de suelo y clima de la Orinoquia, con un producto de alta calidad nutricional, a saber, el aceite de seje.

La composición florística de los bosques de galería estudiados sugiere que estos relictos de bosques aún conservan parte de la historia de congruencia de los bosques andinos, hacia la región del piedemonte, características de la altillanura y elementos propios de la región amazónica. En consecuencia, su protección y conservación son una prioridad. Son reservorio de biodiversidad y tienen una población de palma de seje de alto valor estratégico.

La calidad nutricional del aceite de seje es equivalente o superior al aceite de oliva, siendo este un producto de alto valor económico del uso sostenible del bosque de galería, que podría favorecer su conservación, co-

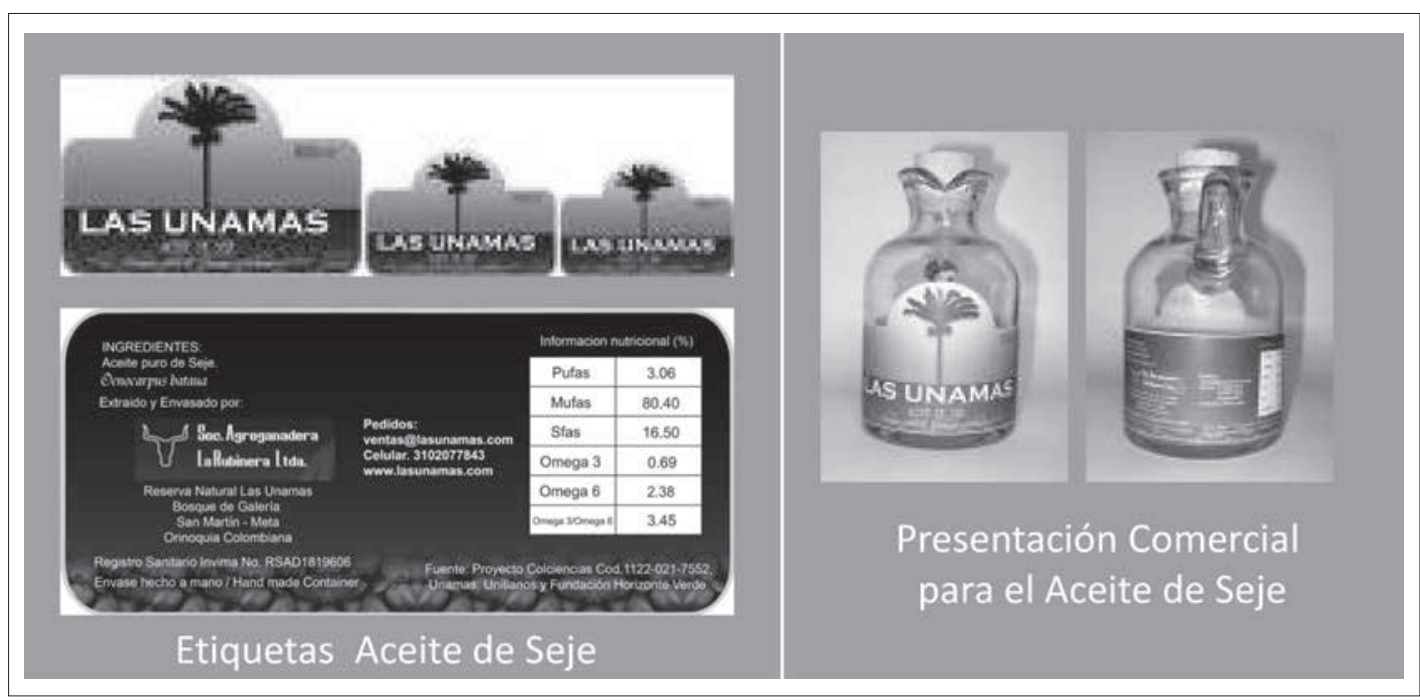

Figura 7. Presentación y empaque para la comercialización del aceite de seje

Aceite de la palma de seje Oenocarpus bataua Mart. por su calidad nutricional puede contribuir a la conservación y uso sostenible de los bosques de galería en la Orinoquia Colombiana 
nocimiento y valoración. Los bosques de galería tienen un alto potencial productivo con la palma de seje y no se deben transformar. Su conservación implica un valor estratégico departamental, regional y nacional.

\section{Agradecimientos}

A Colciencias, Proyecto (cod. 1122-021-7552), Caracterización y uso integral de la palma de seje (Oenocarpus bataua Mart.), recurso natural de alto valor y expresión de la riqueza de la diversidad de palmas de la Orinoquia colombiana; Fundación Horizonte Verde; Reserva Natural Las Unamas; Laboratorios de Suelos y Nutricion Animal de la Universidad de los Llanos y al Laboratorio de Toxicología de la Universidad Nacional de Colombia. Agradecimiento por el apoyo con este manuscrito a la I.A. Tahnee Saleh, convenio Corpometa.

\section{Referencias}

Ávila LM, Diaz JA. 2002. Sondeo del mercado mundial de Aceite de Seje (Oenocarpus bataua Mart.) Instituto de Investigación de Recursos Biológicos Alexander von Humboldt, Bogotá, Colombia, 18 p.

Balick MJ, Gershoff S. Nutritional Evaluation of Jessenia bataua: source of high quality protein and oil from Tropical America. Economic Botany. 1981; 35(3): 261271.

Balick MJ. Palmas Neotropicales: nuevas fuentes de aceites comestibles. Interciencia. 1982; 7:25-29.

Balick MJ. The indigenous palm flora of "Las Gaviotas," Colombia including observations on local names and uses. Bot Mus Leafl. 1985; 30(3):1-34.

Balick MJ. 1992. Jessenia y Oenocarpus: Palmas aceiteras neotropicales dignas de ser domesticadas. Estudio FAO Producción y protección vegetal 88. Roma FAO.

Balslev H, Navarrete H, Paniagua N, Pedersen D, Eiserhardt W, Kristiansen T. El uso de transectos para el estudio de comunidades de palmas. Ecología en Bolivia. 2010; 45(3): 8-22.

Bhatia NP, Sundari K, Adholeya A. 1996. Diversity and selective dominance of vesicular-arbuscular mycorrhizal fungi. In: Mukerji K G, editors. Concepts in Mycorrhizal Research. Kluwer Academic Publishers. P. 133-178.

Blaak (1992). Mechanical extraction and prospects for development of rural industry. En: Balick, H.J. (ed.). Jessenia and Oenocarpus: Neotropical and oil palms worthy of domestication. FAO Plant Production and Protenction Paper No 88. FAO, Roma.

Borgtoft H, Balslev H. 1993. Palmas útiles: Especies ecuatorianas para la agroforestería y extractivismo. Ediciones Abya - Yala. Quito, Ecuador.
Cifufentes L, Moreno F, Arango DA. Fenología reproductiva y productividad de Oenocarpus bataua (Mart.) en bosques inundables del Chocó Biogeográfico, Colombia. Biota Neotrop. 2010; 10(4):101-110.

Collazos E, Mejía M. Fenología y poscosecha de mil pesos Jessenia bataua (Mart) Burret. Acta Agronómica 1988; 38(1):53-63.

Cuevas (2001). Soil versus biological controls on nutrient cycling in Terra Firme Forests.In: M.E. McClain, R.L. Victoria, J.E. Richey (Eds). The biochemistry of Amazon basin.Oxford University Press. p. 53-67.

Ervik (1995). Comparative studies of pollination biology in neotropical palms. PhD thesis, University of Aarhus, Denmark.

Food and Agriculture Organization of the United Nations (FAO). (2011). State of the World's Forest. Rome.

Galeano G, Bernal R. 1987. Palmas del departamento de Antioquia: Región occidental. 1 ed. Universidad Nacional de Colombia, Bogotá.

Galeano G, Bernal R. 2005. Palmas. En: Calderón E, Galeano G. \& N. García (eds.) Libro Rojo de Plantas de Colombia. Volumen II: Palmas, frailejones y zamias. Instituto Alexander von Humboldt, Instituto de Ciencias Naturales-Universidad Nacional de Colombia, Ministerio de Ambiente, Vivienda y Desarrollo Territorial, Bogotá. p 59-223.

Galeano G, Bernal R. 2010. Palmas de Colombia: guía de campo. Universidad Nacional de Colombia, Facultad de Ciencias, Instituto de Ciencias Naturales.

García H.1974. Flora medicinal de Colombia. Instituto de Ciencias Naturales. Universidad Nacional, Bogotá. Vol. I. 561 pp.

García M. 1988. Observaciones de la polinización en Jessenia bataua (Arecaceae) en la reserva de producción faunística Cuyabeno, Amazonia del Ecuador. Tesis en biología Pontificia Universidad Católica del Ecuador.

García (1997). Relación Entre el Consumo de Aceite de Palma y el Nivel de Lípidos Plasmáticos en un Grupo de Consumidores Habituales del Mismo. Lecturas Sobre Nutrición; 4: 73 - 80.

Gentry (1988). Changes in plant community diversity and floristic composition on environmental and geographical gradients. Ann. Missouri Bot. Gard. 75: 1-34.

Henderson (1995). The palms of the Amazon. Oxford University Press, Nueva York, 351 p.

Henderson A, Galeano G, Bernal R. 1995. Field guide to the palms of the Americas. Princeton University Press. Princeton. New Jersey. 352 pp.

Henderson (2002). Evolution and ecology of palms. The New York Botanical Garden Press.

Johnson (1996). Palms: Their conservation and sustained utilization, IUCN, Switzerland, $166 \mathrm{p}$.

Játiva MI, Alarcón R. 1994. Sobre la botánica y la comercialización de ungurahua, Oenocarpus bataua Mart. (Arecacea), en la zona alta del Napo, Ecuador. Pp 53-89. En R. ALARCÓN, P. MENA \& A. SOLDI (eds.). 1994. Etnobotánica, Valoración Económica y Comercialización de Recursos Florísticos Silvestres en el Alto Napo, Ecuador. Ecociencia. Quito. 204 pp. 
Kahn F. Palms as key swamp forest resources in Amazonia. For. Ecol. Manage. 1991; 38: 133-142.

Küchmeister H, Webber A, Gottsberger G, Silberbauer I. A polinização e sua relação com a termogênese em espécies de Arecaceae e Annonaceae da Amazônia Central. Acta Amazonica. 1998; 28:217- 245.

La Rotta C, Miraña P, Miraña M, Miraña B, Miraña M, Yucuna N. 1989. Estudio botánico sobre las especies utilizadas por la comunidad indígena Miraña, amazonas. Váupes, Colombia. WWF-FEN. 30p.

Lasso CA, Rial A, Matallana C, Ramírez W, Señaris J, Díaz A, Corzo G, Machado A. (Eds.). 2011. Biodiversidad de la cuenca del Orinoco. II Áreas prioritarias para la conservación y uso sostenible. Instituto de Investigación de Recursos Biológicos Alexander von Humboldt, Ministerio del Ambiente, Vivienda y Desarrollo Territorial, WWF Colombia, Fundación Omacha, Fundación La Salle de Ciencias Naturales e Instituto de Estudios de la Orinoquia (Universidad Nacional de Colombia). Bogotá, D.C, Colombia. 304 pp.

Martínez LB, Pugnaire FI. Interacciones entre las comunidades de hongos formadores de micorrizas arbusculares y de plantas. Algunos ejemplos en los ecosistemas semiáridos. Ecosistemas. 2009;18 (2): 44-54.

Mejía K. 1988. Utilization of palms in eleven Mestizo villages of the Peruvian Amazon (Ucayali River, Department of Loreto). Advances in Economic Botany, 6: 130-136.

Mejia K. 1992. Las palmeras en los mercados de lquitos. Bull. Inst. fr. etudes andines, 21(2): 755-769.

Miller K. Fruit production of the Ungurahua palm (Oenocarpus bataua Mart. subsp. bataua, Arecaceae) in an indigenous managed reserve. Economic Botany 2002; 56(2): 165-176.

Morcote G, Cabrera G, Mahecha D, Franky CE, Cavelier I.. Las palmas entre los grupos cazadores-recolectores de la Amazonía colombiana. Caldasia, 1998; 20: 57-74.

Núñez LA, Bernal R, Knudsen J. 2005. Diurnal palm pollination by mytropine beetles: is it weather-related? Plant Systematics and Evolution 208:187-196.

Nuñez LA, Rojas R. Biología reproductiva y ecológia de la polinización de la palma milpesos Oenocarpus bataua en los Andes Colombianos. Caldasia. 2008; 30(1):101-125.

Ocampo A. 1997. Sistemas Integrados de Producción: base de la Ganadería del Tercer Milenio. EN: Seminario Internacional 'La ganadería del Tercer Milenio: Sistemas Integrados de Producción'. Banco Ganadero y la Corporación para el Desarrollo Integral del sector Pecuario - CIPEC, Santa fe de Bogotá, 27 al 29 de noviembre.

Ocampo A. 1998. Las Palmas, una estrategia de vida tropical: En: Conferencia electronica sobre Agroforesteria en America Latina Ponencia: Libro: Conferencia electronica sobre Agroforesteria en America Latina, FAO.

Paniagua NY. Diversidad, densidad, distribución y uso de las palmas en la región del Madidi, noreste del departamento de La Paz (Bolivia). Ecología en Bolivia. 2005;40(3): 265-280.

Ruiz M, Garcia C, Sayer JA. Los servicios ambientales de los bosques. Ecosistemas 2007; 16(3): 81-90.

Peters M, Gentry AH, Mendelsohn RO. Valuation of an amazonian rainforest. Nature. 1989; 339: 655-656.
Ríos et al., (1997). Cartilla No. 2. Proceso de germinación, transplante y características del fruto de palma de milpesos Jessenia bataua. Implementación del mejoramiento tecnológico de la extracción artesanal del aceite de palma milpesos Jessenia bataua. Universidad tecnológica del choco.

Romero MH, Galindo G, et al., 2004. Ecosistemas de la Cuenca del Orinoco colombiano. Instituto de Investigación de Recursos Biológicos Alexander von Humboldt. Bogotá. Colombia, 189 p.

Rodríguez S. Organismos del suelo: la dimensión invisible de las invasiones por plantas no nativas. Ecosistemas. 2009; 18(2):32-43.

Salamanca CR. 2004. Validación de la producción masiva de las micorrizas como alternativa agroambiental para los pequeños productores del municipio de Restrepo. Informe final proyecto Corpoica - Pronatta. Corpoica c. I, La Libertad. Villavicencio, Meta. 42 p.

Sarmiento G. 1983. The savannas of tropical America. En: F Bourliere, F. (Ed): Ecosystems of the World XIII. Tropical Savannas, Elsevier, Amsterdam, pp. 245-288.

Sellier 1957. Nombres folclóricos e indígenas de algunas palmeras amazónico-guayanesa con apuntes etnobotánicos. Bol. Soc. Venez. Cienc. Nat. 18 (89): 195-23.

Sieverding E. 1984. Aspectos básicos de la investigación de la micorriza vesículo arbuscular. En: Investigaciones sobre micorrizas en Colombia. E. Sieverding Ed. Palmira, Valle. Facultad de Ciencias Agropecuarias, Universidad Nacional. Colombia, p 1-14.

Sist P, Puig H. 1987. Regeneration, dynamique des populations et dissemination $d^{\prime}$ un palmier de Guyane Francaise: Jessenia bataua (Mart.) Burret subsp. oigocarpa (Griseb, and H. Wendl) Balick. Adansonia 3:317-336.

Sieverding, E. 1991. Vesicular-arbuscular mycorrhizae management in tropical agrosystem. Eschborn, Federal Republic of Germany. Technical cooperation, GTZ. P.p 371

Vallejo Darío 2002. "Oenocarpus bataua, seje"; Colombia Amazónica, separata especies promisorias 1. Corporación Colombiana para la Amazonia -AraracuaraCOA. P.p. 1-19

Van der Heijden MGA, Bardgett RD, Van Straalen NM. The unseen majority: soil microbes as drivers of plant diversity and productivity in terrestrial ecosystems. Ecology Letters. 2008; 11:296-310.

Villachica H. 1996b. Desarrollo de tecnología para producción sostenible de especies autóctonas. Anexo 1.1:1-27.

Wallace A. 1853. Palm trees of the Amazon and their uses. Jothn van Vooerst. Londres, England.

Vélez G. Estudio fenológico de diecinueve frutales silvestres utilizados por las comunidades indígenas de la región de Araracuara-Amazonia colombiana. Colomb. Amaz. 1992; 6:135-186.

WWF. Diagnóstico y definición de prioridades para la conservación y manejo de la Biodiversidad en la Orinoquia colombiana. Informe Técnico. Cali, Mayo de 1998.

Zona S, Henderson A. 1989. A review of animal mediated seed dispersal of palms. Selbyana,11:6-21. 